\title{
Erratum to: Higher spin glueballs from functional methods
}

\author{
Markus Q. Huber ${ }^{1, a}$, Christian S. Fischer ${ }^{1,2, b}$, Hèlios Sanchis-Alepuz ${ }^{3, c}$ \\ ${ }^{1}$ Institut für Theoretische Physik, Justus-Liebig-Universität Giessen, Heinrich-Buff-Ring 16, 35392 Giessen, Germany \\ ${ }^{2}$ Helmholtz Forschungsakademie Hessen für FAIR (HFHF), GSI Helmholtzzentrum für Schwerionenforschung, Campus Gießen 35392, Gießen, \\ Germany \\ ${ }^{3}$ Silicon Austria Labs GmbH, Inffeldgasse 33, 8010 Graz, Austria
}

Published online: 14 January 2022

(C) The Author(s) 2021

Erratum to: Eur. Phys. J. C (2021) 81:1083 https://doi.org/10.1140/epjc/s10052-021-09864-5

In this article, the last six numbers of Table 1 in column 7 were incorrect. They should read as follows (from top to bottom):
$1.439(0.028)$
$2(0.04)$
$1.86(0.04)$
$2.4(0.05)$
$2.27(0.05)$
$2.24(0.06)$

The original article has been corrected.
Open Access This article is licensed under a Creative Commons Attribution 4.0 International License, which permits use, sharing, adaptation, distribution and reproduction in any medium or format, as long as you give appropriate credit to the original author(s) and the source, provide a link to the Creative Commons licence, and indicate if changes were made. The images or other third party material in this article are included in the article's Creative Commons licence, unless indicated otherwise in a credit line to the material. If material is not included in the article's Creative Commons licence and your intended use is not permitted by statutory regulation or exceeds the permitted use, you will need to obtain permission directly from the copyright holder. To view a copy of this licence, visit http://creativecomm ons.org/licenses/by/4.0/.

Funded by $\mathrm{SCOAP}^{3}$.

The original article can be found online at https://doi.org/10.1140/ epjc/s10052-021-09864-5.

a e-mail: markus.huber@physik.jlug.de (corresponding author)

b e-mail: christian.fischer@theo.physik.uni-giessen.de

c e-mail: helios.sanchis-alepuz@silicon-austria.com 